\title{
The critically-ill pediatric hemato-oncology patient: epidemiology, management, and strategy of transfer to the pediatric intensive care unit
}

\author{
Pierre Demaret ${ }^{1 *}$, Geraldine Pettersen ${ }^{1}$, Philippe Hubert ${ }^{2}$, Pierre Teira ${ }^{3}$ and Guillaume Emeriaud ${ }^{1}$
}

\begin{abstract}
Cancer is a leading cause of death in children. In the past decades, there has been a marked increase in overall survival of children with cancer. However, children whose treatment includes hematopoietic stem cell transplantation still represent a subpopulation with a higher risk of mortality. These improvements in mortality are accompanied by an increase in complications, such as respiratory and cardiovascular insufficiencies as well as neurological problems that may require an admission to the pediatric intensive care unit where most supportive therapies can be provided. It has been shown that ventilatory and cardiovascular support along with renal replacement therapy can benefit pediatric hemato-oncology patients if promptly established. Even if admissions of these patients are not considered futile anymore, they still raise sensitive questions, including ethical issues. To support the discussion and potentially facilitate the decision-making process, we propose an algorithm that takes into account the reason for admission (surgical versus medical) and the hemato-oncological prognosis. The algorithm then leads to different types of admission: full-support admission, "pediatric intensive care unit trial" admission, intensive care with adapted level of support, and palliative intensive care. Throughout the process, maintaining a dialogue between the treating physicians, the paramedical staff, the child, and his parents is of paramount importance to optimize the care of these children with complex disease and evolving medical status.
\end{abstract}

Keywords: Oncology, Hematology, Cancer, Stem cell, Transplantation, Graft, Child, Pediatrics, Critical care, Intensive care

\section{Review}

Children represent only $1 \%$ of all patients with malignant neoplasms [1]. Nevertheless, in developed countries, cancer is the second most common cause of death in children older than age 1 year, after trauma [2]. Tumor-related issues as well as the intensity of therapy itself can lead to severe and life-threatening complications that may require admission to a pediatric intensive care unit (PICU).

Historically, these children have been regarded as poor candidates for intensive care. Given their grim prognosis $[3,4]$, their admission to the PICU raised difficult issues, ethically and operationally. During the past decades, there

\footnotetext{
* Correspondence: demaret.pierre@gmail.com

'Division of pediatric critical care medicine, Department of Pediatrics, Sainte-Justine Hospital, Chemin de la Côte-Sainte-Catherine, Montreal H2J3V6, Canada

Full list of author information is available at the end of the article
}

has been a marked improvement in the prognosis of children with cancer (5-year survival increasing from approximately $40 \%$ in the 1970 s to approximately $80 \%$ in the 2000s $[1,5]$ ) as well as their intensive care outcome [6-8].

The objectives of this review are to characterize the specificities of the critically ill child with cancer, to review the organ support strategies that can be offered, and to assist pediatricians, hemato-oncologists, and pediatric intensivists in transitioning these patients to the PICU. Given their specific challenges, children who undergo hematopoietic stem cell transplantation (HSCT) will be discussed separately.

\section{The pediatric hemato-oncologic patient (non-HSCT)} admitted to the PICU

\section{Epidemiology}

One of every three or four children with cancer is admitted to the PICU at least once during the course of their 
illness $[9,10]$. Children with cancer account for less than $10 \%$ of all PICU admissions [11-15].

\section{Reasons for admission}

The main reasons for admission to the PICU are listed in Table 1. Sepsis and respiratory failure are responsible for approximately two-thirds of nonsurgical PICU admissions [12,15-17].

\section{Mortality and prognostic factors}

Mortality is primarily influenced by the type of admission (surgical vs. nonsurgical). Children admitted postoperatively have a very low mortality rate $(0-4 \%)[10,11,17]$. Because their prognosis does not differ from that of the general population of intensive care, they are excluded from the majority of the populations studied.

Mortality of medical cases is higher. The large multicenter study by Dalton et al. $(\mathrm{n}=802)$ demonstrated a $13.3 \%$ mortality rate for children with cancer admitted for nonsurgical causes (30/226) [11]. Smaller singlecenter pediatric series, considering patients admitted to the PICU in the 2000s, have reported a mortality rate ranging from $15 \%$ to $20 \%[15,24]$. These results, although higher than the mortality rate of the general PICU population, are encouraging compared with the $50 \%$ mortality rate reported in the 1980s [16].

As with the general PICU population, the degree of multiorgan failure is systematically related to prognosis; mortality exceeds $70 \%$ if three or more organs are involved $[10,17,20,24]$. The use of mechanical ventilation and/or inotropic support, related to respiratory and/or cardiovascular insufficiency, are other important

Table 1 Reasons for admission to the pediatric intensive care unit (PICU)

\begin{tabular}{|c|c|c|}
\hline & $\begin{array}{l}\text { Pediatric hemato-oncology } \\
\text { patients without HSCT }\end{array}$ & $\begin{array}{l}\text { Children post- } \\
\text { HSCT }\end{array}$ \\
\hline $\begin{array}{l}\text { Postoperative care } \\
\text { (\% of PICU admission) }\end{array}$ & $72 \%[11]$ & $4-16 \%[18,19]$ \\
\hline \multicolumn{3}{|l|}{ Medical reason ${ }^{a}$} \\
\hline Respiratory failure & $26-58 \%[10,15,17,20]$ & $33-88 \%[19,21-23]$ \\
\hline $\begin{array}{l}\text { Airway compression }{ }^{\mathrm{b}} \\
\text { (\% of respiratory failure) }\end{array}$ & $0-48 \%[10,17,20]$ & $0 \%[19,21-23]$ \\
\hline $\begin{array}{l}\text { Lung disease } \\
\text { (\% of respiratory failure) }\end{array}$ & $52-100 \%^{\mathrm{c}}[10,15,17,20]$ & $100 \%{ }^{d}[19,21-23]$ \\
\hline $\begin{array}{l}\text { Severe sepsis/septic } \\
\text { shock }\end{array}$ & $8-36 \%[10,15,17,20,24]$ & $21-36 \%[18,19,21,23]$ \\
\hline Neurological problem & $10-31 \%[10,15,17,20,24]$ & $3-20 \%[18,19,21,25]$ \\
\hline Renal dysfunction & $5-15 \%[10,15,20]$ & $5-8 \%[21,22,25]$ \\
\hline Tumor lysis syndrome & $5-8 \%[10,15]$ & \\
\hline
\end{tabular}

prognostic factors $[10,15,20,24]$. Their combination is associated with a worse prognosis, with mortality reaching $54 \%$ to $100 \%[11,17,20]$. It should be noted that children ventilated because of airway compression have a better outcome than those ventilated for lung disease $[10,12,20]$.

Children admitted to the PICU at the time of diagnosis of oncologic disease, before initiation of chemotherapy, seem to have a better prognosis than those admitted later ( $8 \%$ vs. $34 \%, p=0.06)$ [10]. This difference may be due to differences in the reasons for admission between these two groups and to the toxicity of chemotherapy itself.

Some authors also have reported that the type of cancer influences PICU mortality: children with solid tumors have a lower mortality rate than those with hematological malignancies $[15,24]$.

\section{Cancer and respiratory failure in the PICU}

Respiratory failure is a major cause of PICU admission for children with cancer (Table 1). The term "respiratory failure" is not always clearly defined in the literature addressing this issue. Acute respiratory distress syndrome (ARDS) should be defined according to the American-European Consensus Conference on ARDS criteria [26]: acute onset, $\mathrm{PaO}_{2} / \mathrm{FiO}_{2} \leq 200 \mathrm{mmHg}$ (regardless of positive end-expiratory pressure level), bilateral infiltrates on chest radiograph, and no evidence of left atrial hypertension. The acute lung injury (ALI) criteria only differ by the level of $\mathrm{PaO}_{2} / \mathrm{FiO}_{2}$, which has to be $\leq 300 \mathrm{mmHg}$. The $\mathrm{SpO}_{2} / \mathrm{FiO}_{2}$ ratio could be used in the evaluation of lung disease severity as a surrogate of the $\mathrm{PaO}_{2} / \mathrm{FiO}_{2}$ ratio if an arterial catheter is not available [27].

Noninvasive ventilation (NIV) is of particular interest in these patients who are highly susceptible to infections, because it does not breach the respiratory barrier. The benefits of NIV for immunocompromised patients have been documented in both adults [28-31] and children [32,33].

In a retrospective study of 239 children with cancer admitted to the PICU for respiratory failure, Pancera et al. [32] compared children ventilated for at least 24 hours with NIV (nasal biphasic positive airway pressure) $(\mathrm{n}=120)$ with children ventilated invasively (without prior NIV or with prior NIV $<24$ hours) $(\mathrm{n}=119)$. The success rate of NIV, defined as the absence of subsequent endotracheal intubation, was $74 \%$. In the multivariate analysis, predictors of failure of NIV were: cardiovascular dysfunction, therapeutic intervention score (TISS) $\geq 40$, and presence of a solid tumor. Fortysix patients (39\%) in the invasively ventilated group and 93 (77\%) in the NIV group survived to PICU discharge $(p<0.001)$. There was a significant difference in the 30- 
day survival between the invasively ventilated group (23.3\%) and the NIV group (47\%; $p<0.0001)$. It is important to note that these two groups were derived from standard practice rather than randomization. Therefore, the results need to be interpreted with caution.

Two other retrospective studies by Schiller et al. [33] and Piastra et al. [34] reported data from 14 pediatric hemato-oncology patients with ALI and 23 pediatric hemato-oncology patients with ARDS, respectively. All of these patients received NIV via a full-face mask or a helmet. Intubation was avoided in 12 of 14 and 13 of 23 patients, respectively. Ten of the 12 intubated patients in the two studies died eventually compared with 1 of the 25 nonintubated patients.

Whereas a few randomized, controlled trials conducted in the adult population have shown significant benefits of early implementation of NIV in immunocompromised patients $[28,30,31]$, no randomized trials have been conducted in children with cancer. Studies previously discussed have a significant potential for selection biases (the children who received NIV could be less severely ill than those who did not) and for information biases, inherent to their retrospective nature. However, considering potential complications related to invasive ventilation in the hemato-oncology children, and in light of the benefits of early NIV documented in adults, we believe it is important to consider a trial of NIV in this category of patients.

Despite the benefits of NIV, a difficult question remains: when is the appropriate time to declare NIV a failure and to initiate invasive ventilation in a pediatric hemato-oncology patient whose respiratory function is not improving? Invasive ventilation is documented as a poor prognostic factor among these children but delaying intubation also could worsen their course. To balance these effects, close monitoring is essential in all cases, and a possible switch to invasive ventilation should be discussed if there is no improvement after the first 2 hours of ventilation [35]. The criteria identified as predictive of NIV failure in the general PICU population are the presence of a second organ failure [36], $\mathrm{pH}$ $<7.25$ after 2 hours of treatment [37], the need for a high level of support (mean pressure $>12 \mathrm{cmH}_{2} \mathrm{O}$ or $\left.\mathrm{FiO}_{2}>0.6\right)$ [38], and the presence of ARDS [39].

\section{Cancer and sepsis}

Several factors predispose the child with cancer to sepsis [40,41]: the chemotherapy regimens responsible for prolonged periods of marrow aplasia and disruption of skin and mucosal barriers, the type of tumor (hematological malignancies having a greater risk than solid tumors), the stage of the disease, neutropenia, as well as the presence of comorbidities and indwelling catheters.
Children with cancer in septic shock seem to have a prognosis similar to that of children without cancer, according to work by Pound et al. [40]. In this study, 69 pediatric oncology patients admitted to the PICU with a diagnosis of septic shock (based on the presence of hypo- or hyperthermia, tachycardia, tachypnea and hypotension, and evidence of perfusion abnormalities or organ dysfunction after adequate fluid resuscitation) were compared with a group of age- and gendermatched nononcology patients admitted to the PICU with septic shock during the same time period. No significant difference could be demonstrated with respect to survival status at PICU discharge (16\% vs. $12 \%$ respectively, $p=0.67)$ nor at 30 days post-PICU discharge ( $23 \%$ vs. $15 \%, p=0.38$ ). However, there was a significant difference in mortality at 6 months post-PICU discharge between the two groups $(43 \%$ vs. $16 \%, p=0.01)$, explained by the underlying disease in the oncology patients, with all deaths being secondary to disease progression.

Similar results were found by Kutko et al. [42] who reviewed data from 96 episodes of septic shock (defined as hypo- or hyperthermia with signs of altered perfusion and/or hypotension) in 80 PICU patients. Although this study was not adequately powered for such a comparison, there was no difference in mortality rates between children with cancer $(n=68)$ and without $(n=28 ; 12 \%$ vs. $18 \%$, respectively; $p=0.43$ ).

The definitions of sepsis, severe sepsis, and septic shock in children were established in 2005 by the International Pediatric Sepsis Consensus Conference [43]. Systemic inflammatory response syndrome (SIRS) is defined by the presence of at least two of the followings: hypoor hyperthermia, tachycardia or bradycardia, tachypnea or mechanical ventilation, and elevated or depressed leukocyte count. Sepsis is defined by SIRS in the presence of suspected or proven infection. Sepsis is qualified as severe in case of cardiovascular dysfunction, acute respiratory distress syndrome, or two or more other organ dysfunctions, whereas septic shock is defined by the association of sepsis and cardiovascular dysfunction. Because recruitment of patients in both studies evaluating children with cancer and septic shock preceded the consensus conference $[40,42]$, the authors based the septic shock criteria on the Task Force on Hemodynamic Support from the American College of Critical Care Medicine [44]. These former criteria correspond to the consensus conference definitions of severe sepsis or septic shock, allowing comparison with patients admitted to our PICU with such diagnoses.

The management of children with cancer in septic shock does not differ substantially from that of other children and should follow the recommendations of the Surviving Sepsis Campaign [45]. Broad-spectrum 
empirical antibiotic therapy must be started immediately. Administration of intravenous immunoglobulin may be considered in children with severe sepsis (weak recommendation), although a recent metaanalysis does not recommend their use in current practice in the adult population [46]. According to international guidelines $[47,48]$, hematopoietic growth factors should be part of the treatment of febrile neutropenia in patients at high risk of infectious complications (expected prolonged ( $>10$ days) or profound $\left(<0.1 \times 10^{9} / \mathrm{L}\right)$ neutropenia, uncontrolled primary disease, pneumonia, hypotension, and multiorgan dysfunction) [47] or in patients unresponsive to antibiotics or with life-threatening complications [48]. Granulocyte transfusions are not recommended as a routine treatment and should be reserved for special situations [49].

Finally, extracorporeal blood purification therapies, such as high-volume hemofiltration, hemoadsorption with sorbents, such as polymyxin B, or plasmapheresis have been proposed for adults with sepsis given their immunomodulation potential associated with improvement of different physiologic parameters [50,51]. However, important questions regarding these strategies remain unanswered, and evidence of their usefulness in pediatrics is absent. Large trials are required before extracorporeal blood purification can be considered for standard clinical practice $[50,51]$.

\section{Cancer and extracorporeal life support (ECLS)}

Previously, many have argued that patients with cancer should not receive ECLS [52]. Recently, Gow et al. examined the Extracorporeal Life Support Organisation data from 1992 to 2007 pertaining to patients with a diagnosis of cancer and younger than age 21 years at the time of ECLS $(n=107)$ [53]. Table 2 displays the mortality rates of these patients.

This study showed that the rate of infectious complications was not higher than that observed in children without oncologic disease on ECLS (26\% vs. $13-30 \%$, respectively $[54,55])$. However, cardiovascular and renal complications (renal failure requiring replacement therapy, arterial hypertension, cardiovascular failure requiring inotropic support, and cardiorespiratory arrest) seem to be more common in children with cancer. Based on these data, it does not seem unreasonable to consider ECLS in children with cancer who meet the necessary criteria, including reversible pulmonary and/or heart failure persisting despite maximal medical therapy [53]. In practice, most centers do not exclude children with cancer from their ECLS programs as evidenced by a survey conducted in 118 centers belonging to the Extracorporeal Life Support Organisation. Seventy-eight percent of the surveyed centers stated that cancer was not a
Table 2 Mortality of children with cancer placed on ECMO and comparison with patients without cancer (from [53])

\begin{tabular}{llll}
\hline & Cancer patients & Noncancer patients & $\boldsymbol{p}$ value \\
\hline All ECMO & & & \\
ECMO mortality & $58 \%(62 / 107)$ & & \\
Hospital mortality & $65 \%(70 / 107)$ & & \\
Pulmonary ECMO & & & $<0.0001$ \\
ECMO mortality & $58 \%(50 / 86)$ & $35 \%$ & $<0.0002$ \\
Hospital mortality & $64 \%(55 / 86)$ & $44 \%$ & \\
Cardiac ECMO & & & 0.17 \\
ECMO mortality & $57 \%(8 / 14)$ & $39 \%$ & 0.22 \\
\hline Hospital mortality & $71 \%(10 / 14)$ & $55 \%$ & \\
\hline
\end{tabular}

$E C M O=$ extracorporeal membrane oxygenation.

ancludes 86 pulmonary ECMO, 14 cardiac ECMO, and 7 ECMO for cardiopulmonary resuscitation.

contraindication for ECLS, although it was considered a relative or absolute contraindication in $17 \%$ and $5 \%$ of the centers, respectively [53]. Despite the inherent selection bias (all respondents practiced ECLS), this survey demonstrates that ECLS may be considered as part of the PICU treatment offered to children with cancer.

\section{Children with HSCT in the PICU}

Since the first description of a bone marrow transplant in a patient with leukemia in 1950 [56], indications and modalities of this therapy have considerably evolved and HSCT is now used for a wide array of malignant and nonmalignant diseases. Despite many advances, HSCT is still associated with a variety of complications that pose serious threats to transplant recipients (graft versus host disease (GVHD), severe sepsis, or organ dysfunction) [21,57].

\section{Epidemiology}

In 2008, approximately 2,400 children benefited from HSCT in North America, with nearly $90 \%$ of transplants related to cancer $[58,59]$. The proportion of transplanted children admitted to the PICU varies between $10 \%$ and $20 \%[18,19,21-23,60,61]$ but a rate as high as $44 \%$ has been reported [6]. Patients who received an allogeneic transplant may be at greater risk of being admitted to the PICU than those who received an autologous transplant $[21,22]$ although this is not a constant finding [8]. Patients transplanted late in the course of their disease may be at greater risk of requiring intensive care than those transplanted early [21,22]. Other risk factors for PICU admission identified in allogenic HSCT patients are the presence of GVHD and its severity [21,22], fluid overload [8], and engraftment syndrome [22]. 


\section{Reasons for admission}

The main reasons for admission are listed in Table 1 . Respiratory failure is the leading cause of admission $[19,21$ $23]$ followed by severe sepsis/septic shock $[18,19,21,23]$.

\section{Mortality and prognostic factors}

The prognosis of children post-HSCT admitted to the PICU was previously very grim, especially when invasive ventilation was required. As shown in Table 3, the prognosis for these children has improved during the past decade; the PICU survival of ventilated children postHSCT increased from $<20 \%$ to $>50 \%$ [6-8,18,19,21$23,25,60,61]$. Survival at 6 months also seems to have improved, although data are scarce for children transplanted after 2000.

However, this improvement is questioned by some authors. In a retrospective analysis of a large American database comparing children transplanted in 1997, 2000, and $2003(n=5,699)$, Bratton et al. did not find any difference in mortality across the three study periods amongst children post-HSCT who required invasive ventilation (overall mortality 36\%) [65]. In addition, a meta-analysis conducted by Van Gestel et al. showed that the decrease in the PICU mortality of children postHSCT between 1994 and 2000 was no longer statistically significant after adjustment for the reduction in use of mechanical ventilation observed during this period [66].
Thus, it can be debated whether the overall improvement in mortality is secondary to the optimization of management and a less aggressive (or harmful) ventilatory strategy or is merely due to having less severely ill patients admitted to the PICU.

The prognosis of children post-HSCT admitted to the PICU has to be put into perspective with their overall prognosis, which has substantially improved. The rate of complications that may lead to a PICU admission, such as GVHD, sepsis, and respiratory failure, has decreased as well as the hospital mortality (from 12\% in 1997 to $6 \%$ in $2003(p<0.001))$ [65]. In a recent study, Gooley et al. [67] compared patients transplanted in 1993-1997 and in 2003-2007 and found a 41\% decrease in mortality $(p<0.001)$ along with a significant reduction of almost all of the complications analyzed. Several factors have been identified as contributing to these improved outcomes: more judicious patient selection for transplantation, less toxic conditioning regimens, improved surveillance and early management of infectious complications, changes in the management of GVHD, new ventilatory strategies, and changes in management of severe sepsis $[57,65,67]$.

Predictors of poor prognosis regularly reported in children post-HSCT include the use of mechanical ventilation $[18,19,22,23,25,66]$ (especially in the presence of lung disease $[18,25,63,66])$, the use of inotropic support

Table 3 Survival of children post-HSCT admitted to the pediatric intensive care unit (PICU)

\begin{tabular}{|c|c|c|c|c|c|c|c|}
\hline \multirow[t]{2}{*}{ Author } & \multicolumn{2}{|l|}{$\mathbf{n}$} & \multirow{2}{*}{$\begin{array}{l}\text { Period of } \\
\text { transplant }\end{array}$} & \multicolumn{2}{|c|}{ PICU survival } & \multicolumn{2}{|c|}{ Survival $\geq 6$ months after PICU discharge } \\
\hline & Patients & Admissions & & All & Ventilated & All & Ventilated \\
\hline Nichols [62] & 39 & 39 & $1978-1988$ & $44 \%$ & $9 \%$ & NA & NA \\
\hline Keenan [63] ${ }^{\mathrm{a}}$ & 121 & 121 & 1984-1996 & - & $16 \%$ & - & $7 \%$ \\
\hline Hayes [61] & 39 & 44 & 1987-1997 & $27 \%$ & $15 \%$ & $20.5 \%$ & $12 \%$ \\
\hline Schneider [60] & 28 & 28 & 1989-1998 & $50 \%$ & $36 \%$ & $21 \%$ & $14 \%$ \\
\hline Jacobe $[18]^{\mathrm{b}}$ & 40 & 57 & 1994-1998 & $56 \%$ & $42 \%$ & $27 \%$ & $13 \%$ \\
\hline Hagen $[64]^{b}$ & 86 & 98 & 1990-1999 & - & $41 \%$ & - & $20 \%$ \\
\hline Lamas [25] & 44 & 49 & $1991-2000$ & $37 \%$ & $23 \%$ & $13.6 \%$ & NA \\
\hline Diaz [22] & 42 & 42 & 1993-2001 & $31 \%$ & $21 \%$ & $17 \%$ & NA \\
\hline Leung Cheuk [19] ${ }^{\mathrm{b}}$ & 19 & 24 & 1992 V2002 & $54 \%$ & $15 \%$ & $16 \%$ & NA \\
\hline Tomaske [23] & 23 & 26 & 1998-2001 & $42 \%$ & $15 \%$ & $26 \%$ & NA \\
\hline Gonzalez-Vicent [21] & 36 & 36 & 1998-2002 & $47 \%$ & ND & $44 \%$ & NA \\
\hline \multicolumn{8}{|l|}{ Kache [6] } \\
\hline All & 81 & NA & 1992-2004 & NA & NA & NA & NA \\
\hline 1992-1999 & 48 & NA & 1992-1999 & NA & NA & $6 \%$ & NA \\
\hline 2000-2004 & 33 & NA & 2000-2004 & $64 \%$ & $59 \%$ & NA & NA \\
\hline Van Gestel [7]* & 35 & 38 & 1999-2007 & - & $58 \%$ & - & $51 \%$ \\
\hline Benoît [8] & 19 & 19 & $2002-2004$ & $68 \%$ & $50 \%$ & NA & NA \\
\hline
\end{tabular}

$N A=$ not available.

${ }^{\mathrm{a}}$ Exclusion of patients ventilated $<24 \mathrm{~h}$; ${ }^{\mathrm{b}}$ includes postoperative patients (Jacobe: 2; Hagen: 5; Leung Cheuk: 4; Van Gestel: 1). 
$[21,25,60]$, multiorgan failure $[7,18,19,63]$, and the need for renal replacement therapy $[18,23,60]$. Other prognostic factors, such as hyperbilirubinemia [18,64,68,69], GVHD $[6,18,19,25,60]$, and the type of transplant $[18,21,23,25]$, are more controversial. The underlying condition that prompted the HSCT does not appear to affect prognosis $[23,25]$ nor does the time elapsed between transplant and PICU admission [18,21]. All of these data must be interpreted with caution, because they result from singlecenter retrospective studies, often of small sample size. In the meta-analysis by van Gestel et al. [66], a decrease in mortality over time was observed in the univariate analysis, whereas mechanical ventilation was associated with an increased risk of mortality. Only pulmonary disease remained significantly associated with mortality in the multiple meta-regression analysis [66].

Composite scoring systems can be used to predict or to describe the outcome of groups of patients admitted to the intensive care [70]. These scores can be used for quality assessment, economical assessment, monitoring measurement, and research purposes. Commonly used prognostic scores seem to be of limited value in population of children post-HSCT, because they tend to underestimate the mortality of these patients [18,23,61]. The Pediatric RISk of Mortality score (PRISM score) evaluates the mortality risk based on data collected during the first 24 hours in the PICU [71]. Some authors have proposed to adapt this score by adding important prognostic factors for children post-HSCT, thus creating the Oncological-PRISM score (O-PRISM) [60]. An O-PRISM score $\geq 10$ would suggest an increased risk of mortality $[21,23,72]$. Such a score, which has not yet been validated, could be used to better analyze cohorts of children post-HSCT admitted to PICU and in the evaluation of new treatment strategies.

\section{Children post-HSCT and sepsis}

Severe sepsis/septic shock is still a major cause of PICU admission for children post-HSCT, although its incidence has decreased over the years thanks to the development of anti-infective strategies, the elaboration of reduced-intensity regimens, and better monitoring of subclinical infections [65].

The prognosis of severe sepsis is worse in children post-HSCT than in nontransplanted children with cancer. Fiser et al. analyzed 446 separate PICU admissions of 359 children with cancer with a diagnosis of septic shock (defined as cardiovascular dysfunction requiring fluid boluses or inotropic support in the presence of fever and suspected or proven infection) [73]. PICU mortality was $30 \%$ after HSCT versus $12 \%$ for other cancer patients $(p<0001)$. The logistic regression analysis identified HSCT as one of the factors significantly associated with mortality in children with cancer, requiring both mechanical ventilation and inotropic support (odds ratio 2.9; 95\% confidence interval 1.1-7.4), together with PRISM score, fungal sepsis, and the need for multiple inotropes. Six-month survival was $69 \%$ among non-HSCT children versus 39\% for children post-HSCT $(p<0.01)$. Although these mortality rates are substantial, they are not as bleak as previously feared and should encourage the provision of intensive management of severe sepsis in children post-HSCT.

\section{Renal replacement therapy in children post-HSCT}

Children who have undergone HSCT are at high risk of fluid overload due to voluntary intravenous hyperhydration, infusion of multiple antibiotics, veno-occlusive disease, and multiple transfusions of blood products. In addition, the conditioning regimen may be associated with renal toxicity and with some degree of systemic inflammatory response syndrome accompanied by a capillary leak syndrome [74].

Preventing fluid overload is important in children post-HSCT, because it has been identified as a risk factor for PICU admission in a retrospective study [8]. Moreover, fluid overload worsens the prognosis of patients with hypoxemic respiratory failure [75], a leading cause of PICU admission for children post-HSCT.

The usefulness of renal replacement therapy (RRT) has been questioned in children post-HSCT. Several small retrospective studies have found a mortality rate ranging from $75 \%$ to $100 \%$ in this population receiving RRT [19,23,25]. However, Flores et al. recently reported more encouraging results. The authors reviewed data of 51 children post-HSCT from an American prospective registry of children receiving continuous RRT (CRRT) [76]. They found a PICU mortality rate of 55\%. Patients requiring ventilatory support had a lower survival rate than the nonventilated patients $(35 \%$ vs. $71 \%, p<0.05)$.

RRT could be beneficial through other mechanisms than optimization of fluid balance. DiCarlo et al. reported a series of ten children with cancer (including six HSCT patients) who had developed ARDS and who seemed to have benefited from early high-volume RRT (continuous hemodiafiltration with a flow of $50 \mathrm{ml} / \mathrm{min} /$ $1.73 \mathrm{~m}^{2}$ ) initiated at or near the start of mechanical ventilation, regardless of renal function [77]. Only four of these children had renal dysfunction and fluid overload. Nine of ten patients were extubated and eight survived (follow-up until 18 months after discharge from the PICU), suggesting that early initiation of CRRT in this population could prevent inflammatory lung injuries in addition to fluid overload. This concept is supported by the finding of Rajasekaran et al. of an association between high C-reactive protein serum levels at the end of CRRT and the risk of mortality (33 courses of CRRT among 29 patients) [69]. 
CRRT also may favorably influence oxygenation of children post-HSCT with ALI. Elbahlawan et al. published recently a retrospective analysis of a pediatric HSCT cohort admitted to the PICU and receiving CRRT during a course of mechanical ventilation for ALI [74]. An improvement in oxygenation $\left(\mathrm{PaO}_{2} / \mathrm{FiO}_{2}\right.$ ratio) was observed 24 hours and 48 hours after the beginning of CRRT. This effect is likely to correlate with negative fluid balance. However, only five children survived to PICU discharge (17\%).

Thus, it seems that RRT may be useful in children post-HSCT, particularly in the presence of fluid overload. The concept of using high-dose RRT to promote favorable clearance of inflammatory mediators is attractive, especially because pro- and anti-inflammatory systems are probably dysregulated in these patients. Further studies are required before this indication alone could be retained in current practice.

\section{Proposal of a decisional algorithm for critically ill children with cancer}

Discussions surrounding PICU admission of cancer children may raise difficult and sensitive questions, especially from an ethical standpoint. Establishing PICU admission criteria for children with cancer may facilitate these discussions. To this end, we propose an algorithm (Figure 1) adapted from the adult literature [78], based on consensus opinion of physicians caring for critically ill children with cancer at our institutions. As a result, some items remain subjective and are meant to be discussed case-by-case and modified as needed according to clinical settings. This highlights the paramount importance of constant dialogue between hemato-oncologists and intensivists, as well as with other health care professionals, the child, and his parents. This dialogue is essential to ensure continuity of high-quality care for these children with complex disease and evolving medical status and to benefit from the experience of all those involved in their care.

$\mathrm{PICU}=$ pediatric intensive care unit; HSCT, hematopoietic stem cell transplantation; ECLS = extracorporeal life support. ${ }^{a}$ Unless a decision regarding limitation of care has been made before the intervention; ${ }^{\mathrm{b}}$ The concept of PICU Trial is detailed in the text; ${ }^{\mathrm{C}} \mathrm{New}$ or progressive multiple organ dysfunction syndrome after days 3 to 5 ; ${ }^{\mathrm{d}}$ May be defined as a Karnofsky score $\geq 50 \%$ and a life expectancy $\geq 100$ days.

Similarly to the ICU admission policies recently proposed by Azoulay et al. [78], we offer different PICU admission strategies based on the anticipated prognosis of both the cancer and the condition leading to the PICU. Patients at low risk for mortality should be treated like the

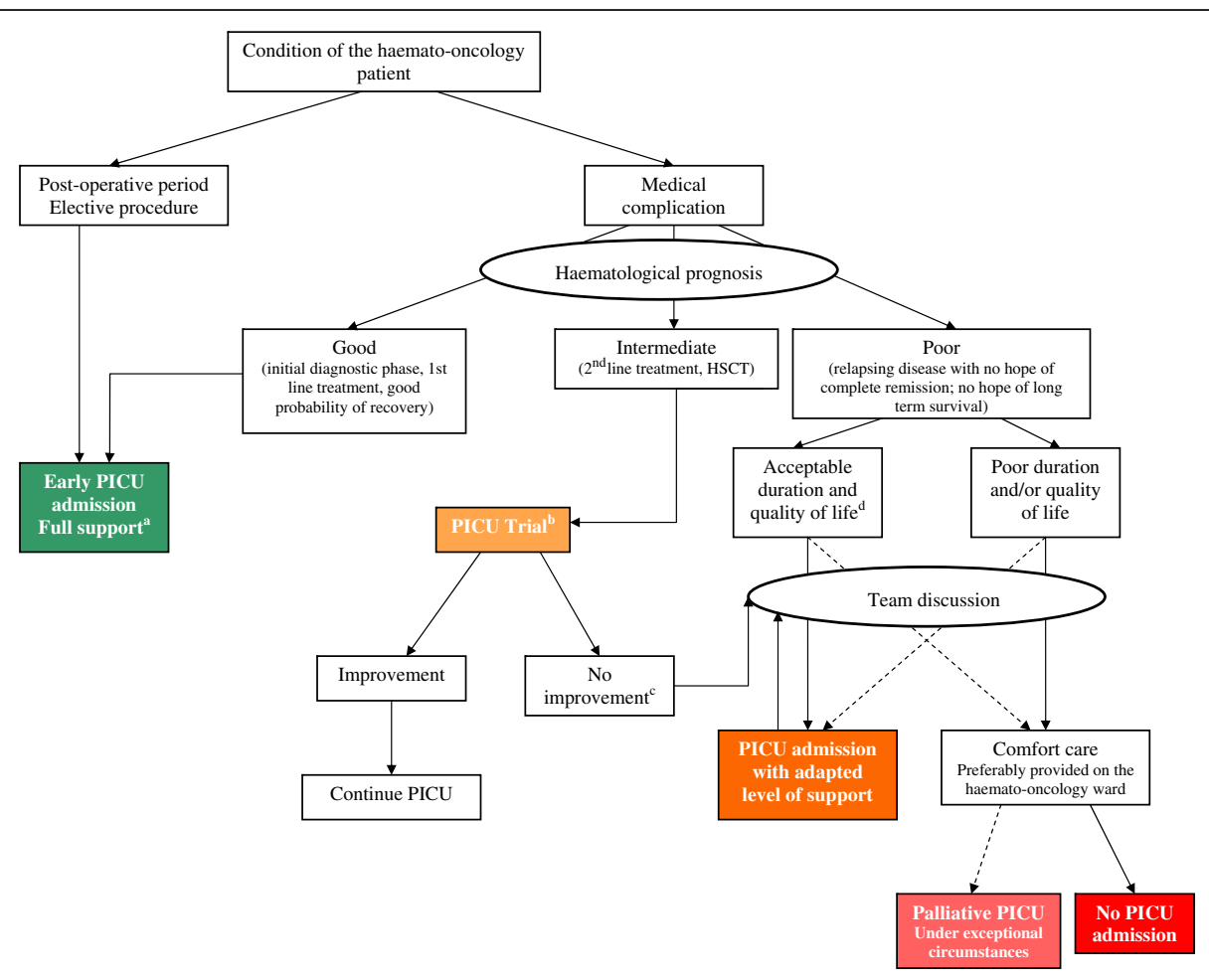

Figure 1 Decisional algorithm for critically ill children with cancer. PICU=pediatric intensive care unit; HSCT, hematopoietic stem cell transplantation; ECLS = extracorporeal life support. ${ }^{\mathrm{a} U n l e s s}$ a decision regarding limitation of care has been made before the intervention; ${ }^{\mathrm{b}}$ The concept of PICU Trial is detailed in the text; ${ }^{C}$ New or progressive multiple organ dysfunction syndrome after days 3 to 5 ; ${ }^{d}$ May be defined as a Karnofsky score $\geq 50 \%$ and a life expectancy $\geq 100$ days. 
general PICU population. This category includes children admitted during the postoperative period and children in the initial phase of the disease. However, as mentioned previously, this classification is an aid to clinical decisions and should not be perceived as unchangeable. For example, some children may have an intermediate or poor prognosis even if they are in the initial phase of the disease, related to the severity of the cancer. The decision to offer a "full support admission" rather than a "PICU trial" (see below) has to result from a multidisciplinary discussion.

Like other authors [79], we consider that the concept of an "ICU trial," developed and studied in the adult population [80], can be adapted to the pediatric population. The ICU trial consists of unlimited ICU support for a fixed time period, usually 3 to 5 days. The patient course is reviewed a few days after ICU admission, because their status at this point is thought to be more representative of their clinical condition and risk of mortality than if such estimation was based on firstICU day values. This could help to identify patients who remain severely ill despite maximal therapy, with no improvement or with worsening condition, in whom difficult decisions, such as limitation of treatment, may be most appropriate $[78,81]$. In particular, the probability of survival is low in patients with persistent or worsening multiple organ failure after 48-72 hours [82-84], as well as in transplanted patients with mechanical ventilation exceeding 2 weeks [82]. As illustrated in the proposed algorithm, the ICU trial is particularly pertinent in critically ill patients with intermediate prognosis of their oncologic disease. With respect to patients with a poor hemato-oncologic prognosis (i.e., patients with no hope of survival), we believe that it is important to distinguish between two groups, according to the anticipated duration and quality of life. Mid-term life expectancy may be considered satisfactory in some patients,for example those having a Lansky score [85] (children aged 0-16 years) or a Karnofsky score [86] (children older than age 16 years) $\geq 50 \%$ and a life expectancy $\geq 100$ days. The Lansky and the Karnofsky scores are validated performance status scales that are widely used to quantify the functional status of cancer patients $[85,86]$. They are frequently used as criteria for selecting patients for eligibility for phase I oncology trials. These patients could benefit from PICU support, after a discussion between the medical team and the family, to establish a reasonable treatment plan adapted to the patient's needs. This plan usually excludes exceptional therapies (ECLS, RRT, high-frequency ventilation) and needs to be reassessed on a daily basis.

On the other hand, patients with an anticipated poor duration and/or quality of life will not benefit from PICU support. The concept of palliative PICU admission has been proposed [78] for patients in whom some specific form of comfort care cannot be provided on the ward; we believe that this situation is exceptional and should be avoided.

Future observational studies are warranted to evaluate this proposed algorithm for PICU admission in children with cancer.

\section{Conclusions}

Children with cancer represent a population at risk for complications that may lead to PICU admission. Their prognosis has improved considerably during the past 20 years as a result of advances in hemato-oncology and intensive care. Children post-HSCT also have benefited from this progress, although they remain at a higher risk of mortality.

Most children with cancer should be admitted to the PICU if necessary and be considered eligible to receive maximal therapy. If after a few days of intensive treatment, there is absence of improvement, or progression of multiple organ failure, the care plan should be reviewed through adaptation of the level of support or guidance toward palliative care. Discussions pertaining to these important decisions should involve the intensivists, the hemato-oncologists, the family, and the patient when capable.

Large epidemiological studies in this population are scarce. Prospective, multicenter studies would lead to a better understanding of this population's specificities and optimize the admission strategies as well as the management of these children in the PICU.

\section{Abbreviations}

ALI: Acute Lung Injury; ARDS: Acute Respiratory Distress Syndrome; ECLS: Extra-Corporeal Life Support; GVHD: Graft Versus Host Disease; HSCT: Hematopoietic Stem Cell Transplantation; NIV: Non Invasive Ventilation; PICU: Pediatric Intensive Care Unit; RRT: Renal Replacement Therapy.

\section{Competing interests}

The authors declare that they have no competing interests.

\section{Acknowledgments}

The authors thank Dr. Catherine Farrell for help reviewing the manuscript.

\section{Author details}

${ }^{1}$ Division of pediatric critical care medicine, Department of Pediatrics, Sainte-Justine Hospital, Chemin de la Côte-Sainte-Catherine, Montreal H2J3V6, Canada. ${ }^{2}$ Division of pediatric critical care medicine, Hôpital NeckerEnfants Malades, Rue de Sèvres, 75007, Paris, France. ${ }^{3}$ Division of pediatric hemato-oncology, Department of Pediatrics, Sainte-Justine Hospital, Chemin de la Côte-Sainte-Catherine, Montreal H2J3V6, Canada.

\section{Author's contributions}

PD carried out the literature review and analysis and drafted the manuscript. GE provided critical input into the draft manuscript. He particularly contributed to the section on respiratory failure. He had the original idea of a decisional algorithm, and drafted the first version with PD. GP, PH and PT all reviewed the draft and provided critical commentary. All authors read and approved the final manuscript.

Received: 16 January 2012 Accepted: 12 June 2012

Published: 12 June 2012 


\section{References}

1. Steliarova-Foucher E, Stiller C, Kaatsch P, Berrino F, Coebergh JW, Lacour B, Parkin M: Geographical patterns and time trends of cancer incidence and survival among children and adolescents in Europe since the 1970s (the ACCIS project): an epidemiological study. Lancet 2004, 364:2097-2105.

2. Davidoff AM: Pediatric oncology. Semin Pediatr Surg 2010, 19:225-233.

3. Butt W, Barker G, Walker C, Gillis J, Kilham H, Stevens M: Outcome of children with hematologic malignancy who are admitted to an intensive care unit. Crit Care Med 1988, 16:761-764.

4. Sivan Y, Schwartz PH, Schonfeld T, Cohen IJ, Newth CJ: Outcome of oncology patients in the pediatric intensive care unit. Intensive Care Med 1991, 17:11-15.

5. Kaatsch P: Epidemiology of childhood cancer. Cancer Treat Rev 2010, 36:277-285

6. Kache S, Weiss IK, Moore TB: Changing outcomes for children requiring intensive care following hematopoietic stem cell transplantation. Pediat Transplant 2006, 10:299-303.

7. van Gestel JP, Bollen CW, Bierings MB, Boelens JJ, Wulffraat NM, van Vught AJ: Survival in a recent cohort of mechanically ventilated pediatric allogeneic hematopoietic stem cell transplantation recipients. Biol Blood Marrow Transplant 2008, 14:1385-1393.

8. Benoit G, Phan V, Duval M, Champagne M, Litalien C, Merouani A: Fluid balance of pediatric hematopoietic stem cell transplant recipients and intensive care unit admission. Pediatr Nephrol 2007, 22:441-447.

9. Rosenman MB, Vik T, Hui SL, Breitfeld PP: Hospital resource utilization in childhood cancer. J Pediatr Hematol Oncol 2005, 27:295-300.

10. Heying R, Schneider DT, Korholz D, Stannigel H, Lemburg P, Gobel U: Efficacy and outcome of intensive care in pediatric oncologic patients. Crit Care Med 2001, 29:2276-2280.

11. Dalton HJ, Slonim AD, Pollack MM: MultiCenter outcome of pediatric oncology patients requiring intensive care. Pediatr Hematol Oncol 2003, 20:643-649

12. Hallahan AR, Shaw PJ, Rowell G, O'Connell A, Schell D, Gillis J: Improved outcomes of children with malignancy admitted to a pediatric intensive care unit. Crit Care Med 2000, 28:3718-3721.

13. Gullberg N, Kalzen H, Luhr O, Gothberg S, Winso O, Markstrom A, Olsson AK, Frostell C: Immediate and 5-year cumulative outcome after paediatric intensive care in Sweden. Acta Anaesthesiol Scand 2008, 52:1086-1095

14. Haase R, Mathony U, Lieser U, Nagel F, Sitka U, Burdach S: Oncology patients in a pediatric intensive care unit-a 7-year experience. Klin Padiatr 2003, 215:234-240.

15. Owens C, Mannion D, O'Marcaigh A, Waldron M, Butler K, O'Meara A: Indications for admission, treatment and improved outcome of paediatric haematology/oncology patients admitted to a tertiary paediatric ICU. Ir J Med Sci 2011, 180:85-89.

16. Heney D, Lewis IJ, Lockwood L, Cohen AT, Bailey CC: The intensive care unit in paediatric oncology. Arch Dis Child 1992, 67:294-298.

17. Dursun O, Hazar V, Karasu GT, Uygun V, Tosun O, Yesilipek A: Prognostic factors in pediatric cancer patients admitted to the pediatric intensive care unit. J Pediatr Hematol Oncol 2009, 31:481-484.

18. Jacobe SJ, Hassan A, Veys P, Mok Q: Outcome of children requiring admission to an intensive care unit after bone marrow transplantation. Crit Care Med 2003, 31:1299-1305.

19. Cheuk DK, Ha SY, Lee SL, Chan GC, Tsoi NS, Lau YL: Prognostic factors in children requiring admission to an intensive care unit after hematopoietic stem cell transplant. Hematol Oncol 2004, 22:1-9.

20. Ben Abraham R, Toren A, Ono N, Weinbroum AA, Vardi A, Barzilay Z, Paret G: Predictors of outcome in the pediatric intensive care units of children with malignancies. J Pediatr Hematol Oncol 2002, 24:23-26.

21. Gonzalez-Vicent M, Marin C, Madero L, Sevilla J, Diaz MA: Risk score for pediatric intensive care unit admission in children undergoing hematopoietic stem cell transplantation and analysis of predictive factors for survival. J Pediatr Hematol Oncol 2005, 27:526-531.

22. Diaz MA, Vicent MG, Prudencio M, Rodriguez F, Marin C, Serrano A, Sevilla J, Casado J, Madero L: Predicting factors for admission to an intensive care unit and clinical outcome in pediatric patients receiving hematopoietic stem cell transplantation. Haematologica 2002, 87:292-298.

23. Tomaske M, Bosk A, Eyrich M, Bader P, Niethammer D: Risks of mortality in children admitted to the paediatric intensive care unit after haematopoietic stem cell transplantation. Br J Haematol 2003, 121:886-891.
24. Meyer S, Gottschling S, Biran T, Georg T, Ehlayil K, Graf N, Gortner L: Assessing the risk of mortality in paediatric cancer patients admitted to the paediatric intensive care unit: a novel risk score?. Eur J Pediatr 2005, 164:563-567.

25. Lamas A, Otheo E, Ros P, Vazquez JL, Maldonado MS, Munoz A, Martos I: Prognosis of child recipients of hematopoietic stem cell transplantation requiring intensive care. Intensive Care Med 2003, 29:91-96.

26. Bernard GR, Artigas A, Brigham KL, Carlet J, Falke K, Hudson L, Lamy M, Legall JR, Morris A, Spragg R: The American-European Consensus Conference on ARDS. Definitions, mechanisms, relevant outcomes, and clinical trial coordination. Am J Respir Crit Care Med 1994, 149:818-824.

27. Khemani RG, Thomas NJ, Venkatachalam V, Scimeme JP, Berutti T, Schneider JB, Ross PA, Willson DF, Hall MW, Newth CJ: Comparison of SpO2 to PaO2 based markers of lung disease severity for children with acute lung injury*. Crit Care Med 2012, 40:1309-1316.

28. Squadrone V, Massaia M, Bruno B, Marmont F, Falda M, Bagna C, Bertone S, Filippini C, Slutsky AS, Vitolo U, et al: Early CPAP prevents evolution of acute lung injury in patients with hematologic malignancy. Intensive Care Med 2010, 36:1666-1674

29. Azoulay E, Alberti C, Bornstain C, Leleu G, Moreau D, Recher C, Chevret S, Le Gall JR, Brochard L, Schlemmer B: Improved survival in cancer patients requiring mechanical ventilatory support: impact of noninvasive mechanical ventilatory support. Crit Care Med 2001, 29:519-525.

30. Antonelli M, Conti G, Bufi M, Costa MG, Lappa A, Rocco M, Gasparetto A, Meduri GU: Noninvasive ventilation for treatment of acute respiratory failure in patients undergoing solid organ transplantation: a randomized trial. JAMA 2000, 283:235-241.

31. Hilbert G, Gruson D, Vargas F, Valentino R, Gbikpi-Benissan G, Dupon M, Reiffers J, Cardinaud JP: Noninvasive ventilation in immunosuppressed patients with pulmonary infiltrates, fever, and acute respiratory failure. $N$ Engl J Med 2001, 344:481-487.

32. Pancera CF, Hayashi M, Fregnani JH, Negri EM, Deheinzelin D, de Camargo B: Noninvasive ventilation in immunocompromised pediatric patients: eight years of experience in a pediatric oncology intensive care unit. J Pediatr Hematol Oncol 2008, 30:533-538

33. Schiller O, Schonfeld T, Yaniv I, Stein J, Kadmon G, Nahum E: Bi-level positive airway pressure ventilation in pediatric oncology patients with acute respiratory failure. J Intensive Care Med 2009, 24:383-388.

34. Piastra M, De Luca D, Pietrini D, Pulitano S, D'Arrigo S, Mancino A, Conti G: Noninvasive pressure-support ventilation in immunocompromised children with ARDS: a feasibility study. Intensive Care Med 2009, 35:1420-1427.

35. Najaf-Zadeh A, Leclerc F: Noninvasive positive pressure ventilation for acute respiratory failure in children: a concise review. Ann Intensive Care 2011, 1:15.

36. Piastra M, De Luca D, Marzano L, Stival E, Genovese O, Pietrini D, Conti G. The number of failing organs predicts non-invasive ventilation failure in children with ALI/ARDS. Intensive Care Med 2011, 37:1510-1516

37. Dohna-Schwake C, Stehling F, Tschiedel E, Wallot M, Mellies U: Noninvasive ventilation on a pediatric intensive care unit: Feasibility, efficacy, and predictors of success. Pediatr Pulmonol 2011, 46:1114-1120.

38. Munoz-Bonet Jl, Flor-Macian EM, Brines J, Rosello-Millet PM, Cruz Llopis M, Lopez-Prats $\mathrm{JL}$, Castillo S: Predictive factors for the outcome of noninvasive ventilation in pediatric acute respiratory failure. Pediatr Crit Care Med 2010, 11:675-680

39. Essouri S, Chevret L, Durand P, Haas V, Fauroux B, Devictor D: Noninvasive positive pressure ventilation: five years of experience in a pediatric intensive care unit. Pediatr Crit Care Med 2006, 7:329-334.

40. Pound CM, Johnston DL, Armstrong R, Gaboury I, Menon K: The morbidity and mortality of pediatric oncology patients presenting to the intensive care unit with septic shock. Pediatr Blood Cancer 2008, 51:584-588.

41. Tamburro R: Pediatric cancer patients in clinical trials of sepsis: factors that predispose to sepsis and stratify outcome. Pediatr Crit Care Med 2005, 6:S87-S91.

42. Kutko MC, Calarco MP, Flaherty MB, Helmrich RF, Ushay HM, Pon S, Greenwald BM: Mortality rates in pediatric septic shock with and without multiple organ system failure. Pediatr Crit Care Med 2003, 4:333-337.

43. Goldstein B, Giroir B, Randolph A: International pediatric sepsis consensus conference: definitions for sepsis and organ dysfunction in pediatrics. Pediatr Crit Care Med 2005, 6:2-8.

44. Carcillo JA, Fields Al: Clinical practice parameters for hemodynamic support of pediatric and neonatal patients in septic shock. Crit Care Med 2002, 30:1365-1378 
45. Dellinger RP, Levy MM, Carlet JM, Bion J, Parker MM, Jaeschke R, Reinhart $K$, Angus DC, Brun-Buisson C, Beale R, et al: Surviving Sepsis Campaign: international guidelines for management of severe sepsis and septic shock: 2008. Crit Care Med 2008, 36:296-327.

46. Alejandria MM, Lansang MA: Dans LF. Mantaring JB: Intravenous immunoglobulin for treating sepsis and septic shock. Cochrane Database Syst Rev; 2010.

47. Smith TJ, Khatcheressian J, Lyman GH, Ozer H, Armitage JO, Balducci L, Bennett CL, Cantor SB, Crawford J, Cross SJ, et al: 2006 update of recommendations for the use of white blood cell growth factors: an evidence-based clinical practice guideline. J Clin Oncol 2006, 24:3187-3205.

48. Aapro MS, Cameron DA, Pettengell R, Bohlius J, Crawford J, Ellis M, Kearney N, Lyman GH, Tjan-Heijnen VC, Walewski J, et al: EORTC guidelines for the use of granulocyte-colony stimulating factor to reduce the incidence of chemotherapy-induced febrile neutropenia in adult patients with lymphomas and solid tumours. Eur J Cancer 2006 42:2433-2453

49. Penack O, Buchheidt D, Christopeit M, von Lilienfeld-Toal M, Massenkeil G, Hentrich M, Salwender H, Wolf HH, Ostermann H: Management of sepsis in neutropenic patients: guidelines from the infectious diseases working party of the German Society of Hematology and Oncology. Ann Oncol 2011, 22:1019-1029.

50. Rimmele T, Kellum JA: Clinical review: blood purification for sepsis. Crit Care 2011, 15:205.

51. Panagiotou A: Gaiao S. Cruz DN: Extracorporeal therapies in sepsis. J Intensive Care Med; 2011 Oct 25 [Epub ahead of print].

52. Green TP, Timmons OD, Fackler JC, Moler FW, Thompson AE, Sweeney MF: The impact of extracorporeal membrane oxygenation on survival in pediatric patients with acute respiratory failure. Pediatric Critical Care Study Group. Crit Care Med 1996, 24:323-329.

53. Gow KW, Heiss KF, Wulkan ML, Katzenstein HM, Rosenberg ES, Heard ML, Rycus PT, Fortenberry JD: Extracorporeal life support for support of children with malignancy and respiratory or cardiac failure: The extracorporeal life support experience. Crit Care Med 2009, 37:1308-1316.

54. Sun HY, Ko WJ, Tsai PR, Sun CC, Chang YY, Lee CW, Chen YC: Infections occurring during extracorporeal membrane oxygenation use in adult patients. J Thorac Cardiovasc Surg 2010, 140:1125-1132.

55. O'Neill JM, Schutze GE, Heulitt MJ, Simpson PM, Taylor BJ: Nosocomial infections during extracorporeal membrane oxygenation. Intensive Care Med 2001, 27:1247-1253.

56. Thomas ED, Lochte HL Jr, Lu WC, Ferrebee JW: Intravenous infusion of bone marrow in patients receiving radiation and chemotherapy. $N$ Engl J Med 1957, 257:491-496.

57. Naeem N, Reed MD, Creger RJ, Youngner SJ, Lazarus HM: Transfer of the hematopoietic stem cell transplant patient to the intensive care unit: does it really matter. Bone Marrow Transplant 2006, 37:119-133.

58. Pasquini MC, Wang Z: Current use and outcome of hematopoietic stem cell transplantation: CIBMTR summary slides. 2010, Available at: http// 841 www.cibmtr.org/.

59. Gratwohl A, Baldomero H, Aljurf M, Pasquini MC, Bouzas LF, Yoshimi A, Szer J, Lipton J, Schwendener A, Gratwohl M, et al: Hematopoietic stem cell transplantation: a global perspective. JAMA 2010, 303:1617-1624.

60. Schneider DT, Lemburg P, Sprock I, Heying R, Gobel U, Nurnberger W: Introduction of the oncological pediatric risk of mortality score $(\mathrm{O}-$ PRISM) for ICU support following stem cell transplantation in children. Bone Marrow Transplant 2000, 25:1079-1086.

61. Hayes C, Lush RJ, Cornish JM, Foot AM, Henderson J, Jenkins I, Murphy P Oakhill A, Pamphilon DH, Steward CG, et al: The outcome of children requiring admission to an intensive care unit following bone marrow transplantation. Br J Haematol 1998, 102:666-670.

62. Nichols DG, Walker LK, Wingard JR, Bender KS, Bezman M, Zahurak ML, Piantadosi S, Frey-Simon M, Rogers MC: Predictors of acute respiratory failure after bone marrow transplantation in children. Crit Care Med 1994, 22:1485-1491.

63. Keenan HT, Bratton SL, Martin LD, Crawford SW, Weiss NS: Outcome of children who require mechanical ventilatory support after bone marrow transplantation. Crit Care Med 2000, 28:830-835.

64. Hagen SA, Craig DM, Martin PL, Plumer DD, Gentile MA, Schulman SR, Cheifetz IM: Mechanically ventilated pediatric stem cell transplant recipients: effect of cord blood transplant and organ dysfunction on outcome. Pediatr Crit Care Med 2003, 4:206-213.
65. Bratton SL, Van Duker H, Statler KD, Pulsipher MA, McArthur J, Keenan HT: Lower hospital mortality and complications after pediatric hematopoietic stem cell transplantation. Crit Care Med 2008, 36:923-927.

66. van Gestel JP, Bollen CW, van der Tweel I, Boelens JJ, van Vught AJ: Intensive care unit mortality trends in children after hematopoietic stem cell transplantation: a meta-regression analysis. Crit Care Med 2008, 36:2898-2904

67. Gooley TA, Chien JW, Pergam SA, Hingorani S, Sorror ML, Boeckh M, Martin PJ, Sandmaier BM, Marr KA, Appelbaum FR, et al: Reduced mortality after allogeneic hematopoietic-cell transplantation. N Engl J Med 2010, 363:2091-2101.

68. Tamburro RF, Barfield RC, Shaffer ML, Rajasekaran S, Woodard P, Morrison RR, Howard SC, Fiser RT, Schmidt JE, Sillos EM: Changes in outcomes (1996-2004) for pediatric oncology and hematopoietic stem cell transplant patients requiring invasive mechanical ventilation. Pediatr Crit Care Med 2008, 9:270-277.

69. Rajasekaran S, Jones DP, Avent Y, Shaffer ML, Elbahlawan L, Henderson N, Barfield RC, Morrison RR, Tamburro RF: Outcomes of hematopoietic stem cell transplant patients who received continuous renal replacement therapy in a pediatric oncology intensive care unit. Pediatr Crit Care Med 2010, 11:699-706.

70. Lacroix J, Cotting J: Severity of illness and organ dysfunction scoring in children. Pediatr Crit Care Med 2005, 6:S126-S134.

71. Pollack MM, Ruttimann UE, Getson PR: Pediatric risk of mortality (PRISM) score. Crit Care Med 1988, 16:1110-1116.

72. Schneider DT, Cho J, Laws HJ, Dilloo D, Gobel U, Nurnberger W: Serial evaluation of the oncological pediatric risk of mortality (O-PRISM) score following allogeneic bone marrow transplantation in children. Bone Marrow Transplant 2002, 29:383-389.

73. Fiser RT, West NK, Bush AJ, Sillos EM, Schmidt JE, Tamburro RF: Outcome of severe sepsis in pediatric oncology patients. Pediatr Crit Care Med 2005, 6:531-536.

74. Elbahlawan L, West NK, Avent Y, Cheng C, Liu W, Barfield RC, Jones DP Rajasekaran S, Morrison RR: Impact of continuous renal replacement therapy on oxygenation in children with acute lung injury after allogeneic hematopoietic stem cell transplantation. Pediatr Blood Cancer 2010, 55:540-545.

75. Raoof S, Goulet K, Esan A, Hess DR, Sessler CN: Severe hypoxemic respiratory failure: part 2-nonventilatory strategies. Chest 2010, 137:1437-1448.

76. Flores FX, Brophy PD, Symons JM, Fortenberry JD, Chua AN, Alexander SR, Mahan JD, Bunchman TE, Blowey D, Somers MJ, et al: Continuous renal replacement therapy (CRRT) after stem cell transplantation. A report from the prospective pediatric CRRT Registry Group. Pediatr Nephrol 2008, 23:625-630.

77. DiCarlo JV, Alexander SR, Agarwal R, Schiffman JD: Continuous venovenous hemofiltration may improve survival from acute respiratory distress syndrome after bone marrow transplantation or chemotherapy. J Pediatr Hematol Oncol 2003, 25:801-805.

78. Azoulay E, Soares M, Darmon M, Benoit D, Pastores SM, Afessa B: Intensive care of the cancer patient: recent achievements and remaining challenges. Ann Intensive Care 2011, 1:5

79. La commission d'éthique de la société française d'hématologie (SFH), la société de réanimation en langue française (SRLF), le groupe francophone de réanimation et urgences pédiatriques (GFRUP): Aspects cliniques et éthiques du transfert en réanimation des patients porteurs d'hémopathies malignes. Réanimation 2010, 19:699-705.

80. Lecuyer L, Chevret S, Thiery G, Darmon M, Schlemmer B, Azoulay E: The ICU trial: a new admission policy for cancer patients requiring mechanical ventilation. Crit Care Med 2007, 35:808-814.

81. Azoulay E, Afessa B: The intensive care support of patients with malignancy: do everything that can be done. Intensive Care Med 2006, 32:3-5.

82. Larche J, Azoulay E, Fieux F, Mesnard L, Moreau D, Thiery G, Darmon M, Le Gall JR, Schlemmer B: Improved survival of critically ill cancer patients with septic shock. Intensive Care Med 2003, 29:1688-1695.

83. Guiguet M, Blot F, Escudier B, Antoun S, Leclercq B, Nitenberg G: Severityof-illness scores for neutropenic cancer patients in an intensive care unit: Which is the best predictor? Do multiple assessment times improve the predictive value. Crit Care Med 1998, 26:488-493. 
84. Martin PL: To stop or not to stop: how much support should be provided to mechanically ventilated pediatric bone marrow and stem cell transplant patients?. Respir Care Clin N Am 2006, 12:403-419.

85. Lansky SB, List MA, Lansky LL, Ritter-Sterr C, Miller DR: The measurement of performance in childhood cancer patients. Cancer 1987, 60:1651-1656.

86. Mor V, Laliberte L, Morris JN, Wiemann M: The Karnofsky Performance Status Scale. An examination of its reliability and validity in a research setting. Cancer 1984, 53:2002-2007.

doi:10.1186/2110-5820-2-14

Cite this article as: Demaret et al:: The critically-ill pediatric hemato-

oncology patient: epidemiology, management, and strategy of transfer

to the pediatric intensive care unit. Annals of Intensive Care 2012 2:14.

\section{Submit your manuscript to a SpringerOpen ${ }^{\circ}$ journal and benefit from:}

- Convenient online submission

- Rigorous peer review

- Immediate publication on acceptance

- Open access: articles freely available online

- High visibility within the field

- Retaining the copyright to your article

Submit your next manuscript at $\gg$ springeropen.com 